\title{
PENDUGAAN ANGKA KEMISKINAN DI KABUPATEN PADANG PARIAMAN MENGGUNAKAN SMALL AREA ESTIMATION DENGAN PENDEKATAN HIERARCHICAL BAYESIAN (HB) LOGLOGISTIK
}

\author{
JUSRI REPI BASRI YULIANI, MAIYASTRI, RITA DIANA \\ Program Studi S1 Matematika, \\ Fakultas Matematika dan Ilmu Pengetahuan Alam, Universitas Andalas, \\ Kampus UNAND Limau Manis Padang, Indonesia. \\ email : jusrirefy@gmail.com
}

Diterima 22 Juni 2019 Direvisi 6 Juli 2019 Dipublikasikan 4 Agustus 2019

\begin{abstract}
Abstrak. Penelitian ini mengkaji tentang pendekatan Hierarchical Bayesian (HB) Loglogistik yang diaplikasikan pada Small Area Estimation (SAE) dengan tujuan mengestimasi tingkat kemiskinan di Kabupaten Padang Pariaman. Metode pendugaan area kecil yang digunakan pada penelitian ini adalah model level area dasar (basic area level model) dengan bantuan variabel penyerta yang tersedia pada level kecamatan. Variabel penyerta yang digunakan pada penelitian ini yaitu rasio SLTA/Sederajat $\left(X_{1}\right)$, persentase keluarga pertanian $\left(X_{2}\right)$, rasio industri mikro kecil $\left(X_{3}\right)$, persentase buruh tani dalam setiap anggota keluarga $\left(X_{4}\right)$, kepadatan penduduk $\left(X_{5}\right)$, dan persentase penduduk pelanggan listrik PLN $\left(X_{6}\right)$. Bentuk integrasi yang kompleks dari sebaran peluang bersyarat pada model diselesaikan menggunakan Markov Chain Monte Carlo (MCMC) dengan menerapkan algortima Gibbs Sampling dan bantuan software WinBugs 1.4.3. Hasil estimasi menggunkan model HB yang diperoleh dibandingkan dengan hasil estimasi pendugaan langsung dengan memperhatikan nilai standard error sebagai tolok ukurnya. Hasil pendugaan tingkat kemiskinan untuk level kecamatan di Kabupaten Padang Pariaman dengan model HB menunjukkan nilai standard error yang kecil.
\end{abstract}

Kata Kunci: Tingkat kemiskinan, Small Area Estimation, Hierarchical Bayesian

\section{Pendahuluan}

Masalah kemiskinan masih menjadi salah satu masalah yang harus dihadapi hampir di seluruh wilayah Indonesia. Masalah kemiskinan ini berkaitan dengan masalah aspek sosial, ekonomi, nudaya dan aspek lainnya. Pemerintah melalui Badan Pusat Statistik (BPS) sampai saat ini masih menggunakan Survei Sosial Ekonomi Nasional (Susenas) untuk menghasilkan ukuran kemiskinan di seluruh daerah. Akan tetapi, survei ini tidak dirancang untuk mendapatkan hasil pada level area kecil (seperti kecamatan/desa) dikarenakan ukuran sampel yang relatif kecil, sehingga data yang tersedia saat ini hanya sampai level kabupaten/kota saja. Jika dilakukan estimasi langsung pada area yang memiliki ukuran sampel yang kecil dengan hanya memanfaatkan data dari area tersebut, maka akan menghasilkan standard error 
yang besar sehingga pendugaan indikator tingkat kemiskinan yang didasarkan pada kondisi tersebut akan menjadi kurang akurat [7].

Untuk mengatasi permasalahan ini, tentunya diperlukan metode estimasi yang dapat memberikan tingkat keakuratan yang lebih baik yaitu dengan menggabungkan antara data survei dengan data pendukung lain misalnya dari data sensus sebelumnya yang memuat variabel dengan karakteristik yang sama dengan data survei [6]. Salah satu metode estimasi yang dapat digunakan yaitu Small Area Estimation (SAE). Metode SAE ini mempelajari metode estimasi tidak langsung yang meminjam kekuatan (borrow strength) dari area lain, biasanya dengan sebuah model yang menghubungkan area-area yang ada melalui pemanfaatan informasi/variabel tambahan dari sensus atau survei lain yang berskala nasional $[6]$.

Berbagai metode SAE telah banyak dikembangkan terutama yang berbasis model (model-based estimation) salah satunya yaitu Hierarchical Bayesian (HB). Metode ini dipilih karena mengingat model HB mampu mengatasi permasalahan pemodelan hirarki untuk jumlah data yang sedikit dan tidak seimbang [3] dengan mengharapkan hasil estimasi yang cukup baik. Berdasarkan hasil uji kesesuaian distribusi terhadap data tingkat kemiskinan Kabupaten Padang Pariaman menggunakan uji Kolmogorov-Smirnov, diperoleh nilai statistik Kolmogorov Smirnov untuk distribusi loglogistik adalah 0,14648 dan p-value adalah 0,80903. Karena p-value lebih besar dari 0,05 maka dapat disimpulkan bahwa tingkat kemiskinan di Kabupaten Padang Pariaman mengikuti distribusi loglogistik. Oleh karena itu, tingkat kemiskinan level kecamatan di Kabupaten Padang Pariaman dapat diduga dengan pendekatan Hierarchical Bayesian Loglogistik.

\section{Landasan Teori}

\subsection{Distribusi Loglogistik}

Distribusi Loglogistik (LL) merupakan distribusi peluang kontinu untuk peubah acak tak-negatif. Distribusi Loglogistik memiliki fungsi kepekatan yaitu [4]:

$$
f(y \mid \mu, \sigma)=\frac{\exp \left(\frac{\ln y-\mu}{\sigma}\right)}{y \sigma\left[1+\exp \left(\frac{\ln y-\mu}{\sigma}\right)\right]^{2}}, y, \mu, \sigma>0
$$

dengan $\mu$ merupakan parameter lokasi dan $\sigma$ merupakan parameter skala.

\subsection{Metode Bayes}

Misalkan terdapat suatu parameter yang menjadi perhatian dan merupakan suatu vektor $\beta=\left(\beta_{1}, \beta_{2}, \cdots, \beta_{k}\right)^{T}$ yang diberikan oleh data observasi $\boldsymbol{y}$ dan $\boldsymbol{y}=$ $\left(y_{1}, y_{2}, \cdots, y_{n}\right)^{T}$ merupakan suatu peubah acak berukuran $n \times 1$, maka distribusi probabilitas untuk posterior $\beta$ pada data $\boldsymbol{y}$ akan proposional dengan perkalian antara distribusi prior $\beta$ dan fungsi likelihood $\beta$ yang diberikan oleh data $\boldsymbol{y}$. Secara 
matematis dapat ditulis sebagai berikut [5]:

$$
f(\boldsymbol{\beta} \mid \boldsymbol{y})=\frac{f(\boldsymbol{y} \mid \boldsymbol{\beta}) f(\boldsymbol{\beta})}{f(\boldsymbol{y})}, f(\boldsymbol{\beta} \mid \boldsymbol{y}) \propto f(\boldsymbol{y} \mid \boldsymbol{\beta}) f(\boldsymbol{\beta})
$$

dengan $f(\boldsymbol{\beta} \mid \boldsymbol{y})$ merupakan distribusi posterior $\boldsymbol{\beta}$ pada data $\boldsymbol{y}, f(\boldsymbol{y} \mid \boldsymbol{\beta})$ merupakan fungsi likelihood $\boldsymbol{\beta}$ yang diberikan oleh data $\boldsymbol{y}, f(\boldsymbol{\beta})$ merupakan distribusi prior dari $\boldsymbol{\beta}$ sebelum dilakukan pengamatan, dan $f(\boldsymbol{y})$ merupakan normalizing constant yang tidak berpengaruh pada parameter.

\subsection{Small Area Estimation (SAE)}

SAE menggunakan pendekatan estimasi tidak langsung, yaitu dengan meminjam kekuatan area lain melalui pemanfaatan informasi/variabel tambahan dari data sensus atau survei berskala nasional [6]. Pada penelitian ini, model yang digunakan adalah model level area dasar (basic area level model) karena data respon yang digunakan merupakan data pada area tertentu yaitu pada level area kecamatan.

Diasumsikan $\mu_{i}$ merupakan suatu fungsi yang menghubungkan parameter $\beta$ dengan variabel penyerta dari area kecil yaitu $x_{i}=\left(x_{1 i}, x_{2 i}, \cdots, x_{k i}\right)^{T}$ yang merupakan suatu vektor dan $i$ merupakan banyaknya area.

Variabel penyerta tersebut digunakan untuk membangun suatu model linier, yaitu:

$$
\mu_{i}=\boldsymbol{x}_{i}^{T} \boldsymbol{\beta}+u_{i}, \quad i=1,2, \cdots, n
$$

dengan $\mu_{i}$ merupakan parameter area kecil yang akan diduga, $\beta=\left(\beta_{1}, \beta_{2}, \cdots, \beta_{k}\right)$ parameter berukuran $k \times 1$ untuk data pendukung $\boldsymbol{x}_{i}$, dan $u_{i}$ merupakan pengaruh acak pada area ke- $i$ yang diasumsikan $u_{i} \sim N\left(0, \sigma_{u}^{2}\right)$.

Jika diasumsikan penduga langsung $\widehat{Y}_{i}$ telah tersedia, maka menurut [6] berdasarkan metode James-Stein yaitu:

$$
\widehat{Y}_{i}=\mu_{i}+e_{i}, i=1,2, \cdots, n
$$

dengan $e_{i}$ adalah sampling error pada area ke- $i$ yang diasumsikan $e_{i} \sim N\left(0, D_{i}\right)$ dan $D_{i}$ diketahui.

Dengan menggabungkan model pada Persamaan 2.3 dan 2.4 di atas, maka akan diperoleh model gabungan sebagai berikut:

$$
\widehat{Y}_{i}=\boldsymbol{x}_{i}^{T} \boldsymbol{\beta}+u_{i}+e_{i}, \quad i=1,2, \cdots, n .
$$

Model gabungan pada Persamaan 2.5 merupakan dengan bentuk khusus dari model pengaruh campuran atau model linier campuran $[6]$.

\subsection{Metode $\mathrm{HB}$ pada $\mathrm{SAE}$}

Pada penelitian ini, model HB yang digunakan adalah model distribusi Loglogistik dengan variabel prediktor berbasis area. Model tersebut didefinisikan sebagai berikut [6]:

(1) Sampling model.

$y_{i} \mid \mu \sim L L\left(\mu, \sigma_{[y]}\right), \sigma_{[y]}$ merupakan ragam dari distribusi loglogistik. 
(2) Linking model.

$\mu=x \beta+u$, dengan $u \sim N\left(0, \sigma_{[u]}^{2}\right)$ dan $\sigma_{[u]}^{2}=\frac{1}{\tau_{[u]}}$.

(3) $\beta$ dan $\sigma_{[u]}^{2}$ saling bebas dengan $\tau_{[u]} \sim \operatorname{Unif}(0,100)$ dan $\beta \sim N\left(\mu_{[\beta]}, \sigma_{[\beta]}^{2}\right)$.

\subsection{Konsep Kemiskinan}

Kemiskinan adalah kondisi kehidupan seseorang yang pengeluaran per kapitanya selama satu bulan tidak mencukupi untuk memenuhi kebutuhan standar hidup minimum [7]. Menurut [1], kebutuhan standar hidup adalah batas minimum pengeluaran per kapita per bulan untuk memenuhi makanan dan non-makanan yang digambarkan dengan suatu garis kemiskinan (GK). GK adalah ratarata pengeluaran perkapita perbulan yang digunakan untuk mengklarifikasikan penduduk ke dalam golongan miskin atau tidak miskin [2].

\section{Pembahasan}

\subsection{Data}

Sumber data yang digunakan pada penelitian ini bersumber dari mikro data Susenas 2017, data Podes 2014 dan data pada Publikasi Kabupaten Padang Pariaman dalam Angka 2016 yang dihasilkan oleh Badan Pusat Statistik (BPS). Berdasarkan studi literatur pada penelitian-penelitian sebelumnya, variabel prediktor yang digunakan yaitu rasio SLTA/sederajat $\left(X_{1}\right)$, persentase keluarga pertanian $\left(X_{2}\right)$, rasio industri mikro kecil (IMK) $\left(X_{3}\right)$, persentase buruh tani dalam setiap anggota keluarga $\left(X_{4}\right)$, kepadatan penduduk $\left(X_{5}\right)$, dan persentase penduduk pelanggan listrik PLN $\left(X_{6}\right)$.

\subsection{Hasil}

Jika suatu variabel acak $Y$ yang berdistribusi Loglogistik yaitu $y_{i} \sim L L\left(\mu, \sigma_{[y]}\right)$ dengan $\mu=x \beta+u, \sigma_{[y]}^{2}=\frac{1}{\tau_{[y]}}$ dan $\mu \sim N\left(x \beta, \sigma_{[u]}^{2}\right), u \sim N\left(0, \sigma_{[u]}^{2}\right)$, dan $\sigma_{[u]}^{2}=$ $\frac{1}{\tau_{[u]}}$, maka model Small Area Estimation dengan pendekatan HB menggunakan data tersebut juga akan berdasarkan distribusi Loglogistik dengan prior yang digunakan pada model ini yaitu $\beta_{j}, \tau_{[y]}$ dan $\tau_{[u]}$.

Fungsi likelihood datanya adalah sebagai berikut:

$$
\begin{aligned}
f\left(\boldsymbol{y} \mid \boldsymbol{\beta}, \tau_{[y]}\right) & =\prod_{i=1}^{n} f\left(y_{i} \mid \boldsymbol{\beta}, \tau_{[y]}\right) \\
& =\prod_{i=1}^{n}\left(\frac{\exp \left(\frac{\ln \left(y_{i}\right)-\mu}{\sigma}\right)}{y_{i} \sigma\left[1+\exp \left(\frac{\ln \left(y_{i}\right)-\mu}{\sigma}\right)\right]^{2}}\right),
\end{aligned}
$$




$$
=\frac{\tau_{[y]}^{\frac{n}{2}} \exp \left(\tau_{[y]}^{\frac{1}{2}} \sum_{i=1}^{n} \ln \left(y_{i}\right)-\mu\right)}{\prod_{i=1}^{n} y_{i}\left[1+\exp \left(\tau_{[y]}^{\frac{1}{2}} \sum_{i=1}^{n} \ln \left(y_{i}\right)-\mu\right)\right]^{2}}
$$

Pada penelitian ini, distribusi prior yang digunakan adalah distribusi prior konjugat dan distribusi prior non-informatif. Untuk parameter $\beta_{j}$ dan $\tau_{[y]}$ merupakan distribusi prior konjugat sedangkan parameter $\tau_{[u]}$ merupakan distribusi prior non-informatif. Distribusi prior untuk masing-masing parameter yang akan diestimasi yaitu

$$
\beta_{j} \sim N\left(\mu_{[\beta]_{j}}, \sigma_{[\beta]_{j}}^{2}\right), \tau_{[y]} \sim \operatorname{Gamma}\left(a_{\tau_{[y]}}, b_{\tau_{[y]}}\right), \tau_{[u]} \sim \operatorname{Uniform}(0,100) .
$$

Kombinasi antar fungsi likelihood dan distribusi prior gabungan akan membentuk distribusi posterior gabungan dari seluruh parameter yang akan diestimasi.

Bentuk proposional distribusi posterior sebagai berikut:

$$
f\left(\beta, \tau_{[y]}, \tau_{[u]} \mid \boldsymbol{y}\right) \propto f\left(\boldsymbol{y} \mid \beta, \tau_{[y]}\right) \times f(u) \times f\left(\beta, \tau_{[y]}, \tau_{[u]}\right) .
$$

$f(u)$ merupakan pengaruh acak pada SAE yang didekati dengan distribusi normal, yaitu:

$$
f(u)=\left(\frac{\tau_{u}^{\frac{n}{2}}}{\sqrt{2 \pi}} \exp \left(-\frac{\tau_{u}^{\frac{1}{2}}}{2}\left(\mu_{i}-x_{i j} \beta\right)^{2}\right)\right)
$$

sehingga:

$$
\begin{aligned}
f\left(\beta, \tau_{[y]}, \tau_{[u]} \mid \boldsymbol{y}\right) \propto & \frac{\tau_{[y]}^{\frac{n}{2}} \exp \left(\tau_{[y]}^{\frac{1}{2}} \sum_{i=1}^{n} \ln \left(y_{i}\right)-\mu\right)}{\prod_{i=1}^{n} y_{i}\left[1+\exp \left(\tau_{[y]}^{\frac{1}{2}} \sum_{i=1}^{n} \ln \left(y_{i}\right)-\mu\right)\right]^{2}} \\
& \times \tau_{[u]}^{\frac{n}{2}} \exp \left(-\frac{\tau_{[u]}}{2} \sum_{i=1}^{n}\left(\mu_{i}-\sum_{j=1}^{k} x_{i j} \beta_{j}\right)^{2}\right), \\
& \times \tau_{[\beta]_{j}}^{\frac{1}{2}} \exp \left(-\frac{\tau_{[\beta]_{j}}}{2}\left(\beta_{j}-\mu_{[\beta]_{j}}\right)^{2}\right) \\
& \times\left(\tau_{[y]}\right)^{a}\left(\tau_{[y]}\right)^{-1} \exp \left(-b_{\tau_{[y]}} \times \tau_{[y]}\right) .
\end{aligned}
$$

Dari distribusi posterior gabungan di atas dapat dicari distribusi posterior marginal dari masing-masing parameter dengan melakukan perhitungan menggunakan metode MCMC dengan algoritma Gibss Sampling melalui bentuk full conditional posterior. Banyaknya update yang dijalankan adalah 10.000 dengan thin 60.000. Pendugaan dilakukan dengan bantuan software WinBUGS. Untuk hasil estimasi masing-masing parameter disajikan pada Tabel 1.

Tabel 1 menunjukkan bahwa dengan nilai $\beta_{0}=-3,058000$ dan $\beta_{2}=0,001794$ secara statistik memiliki pengaruh yang signifikan terhadap Tingkat Kemiskinan di Kabupaten Padang Pariaman. Hal ini dapat dilihat berdasarkan nilai parameter 
Tabel 1. Nilai Estimasi Parameter Model Small Area Estimation dan Credible Interval untuk Data Tingkat Kemiskinan dengan Hierarchical Bayesian (HB) Loglogistik

\begin{tabular}{|c|c|c|c|c|}
\hline Parameter & $\begin{array}{c}\text { Nilai } \\
\text { Estimasi }\end{array}$ & $\begin{array}{c}\text { Standar } \\
\text { Deviasi }\end{array}$ & $\begin{array}{c}\text { MC } \\
\text { Error }\end{array}$ & Credible Interval \\
\hline$\beta_{0}$ & $-3,058000$ & 0,6019 & 0,012050 & $-4,209000 \leq \beta_{0} \leq-1,83200$ \\
\hline$\beta_{1}$ & 0,001718 & 0,001616 & 0,000031 & $-0,001439 \leq \beta_{1} \leq 0,004934$ \\
\hline$\beta_{2}$ & 0,001794 & 0,003543 & 0,000068 & $0,010890 \leq \beta_{2} \leq 0,024860$ \\
\hline$\beta_{3}$ & $-0,000148$ & 0,000394 & 0,000009 & $-0,000947 \leq \beta_{3} \leq 0,000626$ \\
\hline$\beta_{4}$ & 0,000325 & 0,002215 & 0,000043 & $-0,004183 \leq \beta_{4} \leq 0,004757$ \\
\hline$\beta_{5}$ & $-0,000009$ & 0,000193 & 0,000004 & $-0,000393 \leq \beta_{5} \leq 0,000381$ \\
\hline$\beta_{6}$ & $-0,006516$ & 0,005841 & 0,000123 & $-0,018670 \leq \beta_{6} \leq 0,004889$ \\
\hline$\tau_{[u]}$ & 0,011130 & 0,010020 & 0,000150 & $0,001856 \leq \tau_{[u]} \leq 0,031170$ \\
\hline$\tau_{[y]}$ & 0,008493 & 0,014950 & 0,000217 & $0,000001 \leq \tau_{[y]} \leq 0,052160$ \\
\hline
\end{tabular}

yang berada pada credible interval yang tidak melewati titik nol. Jika ditinjau dari ukuran kebaikan, hasil estimasi parameter dengan nilai MC error untuk setiap parameter yang diestimasi sudah berada di bawah $5 \%$ dari nilai standar deviasinya sehingga dapat dikatakan hasil estimasi dari parameter model sudah baik.

Selanjutnya dilihat perbandingan hasil estimasi menggunakan metode penduga langsung dan metode HB Loglogistik dengan melihat nilai standard error keduanya. Hasil estimasinya dapat dilihat pada Tabel 2.

Berdasarkan Tabel 2, hasil estimasi tingkat kemiskinan menggunakan model Small Area Estimation dengan pendekatan Hierarchical Bayesian (HB) Loglogistik mempunyai nilai standard error lebih kecil jika dibandingkan dengan estimasi tingkat kemiskinan menggunakan penduga langsung.

\section{Kesimpulan}

(1) Jika variabel $y_{i}$ berdistribusi Loglogistik atau $y_{i} \sim L L\left(\mu, \sigma_{[y]}\right)$, maka model Small Area Estimation dengan pendekatan Hierarchical Bayesian (HB) menggunakan data tingkat kemiskinan juga berdasarkan distribusi Loglogistik. Fungsi likelihood dari model Small Area Estimation yang mengikuti distribusi Loglogistik adalah:

$$
f\left(\boldsymbol{y} \mid \boldsymbol{\beta}, \tau_{[y]}\right)=\frac{\tau_{[y]}^{\frac{n}{2}} \exp \left(\tau_{[y]}^{\frac{1}{2}} \sum_{i=1}^{n} \ln \left(y_{i}\right)-\mu\right)}{\prod_{i=1}^{n} y_{i}\left[1+\exp \left(\tau_{[y]}^{\frac{1}{2}} \sum_{i=1}^{n} \ln \left(y_{i}\right)-\mu\right)\right]^{2}}
$$

Distribusi prior yang digunakan untuk masing-masing parameter yang akan diestimasi yaitu

$$
\beta_{j} \sim N\left(\mu_{[\beta]_{j}}, \sigma_{[\beta]_{j}}^{2}\right), \tau_{[y]} \sim \operatorname{Gamma}\left(a_{\tau_{[y]}}, b_{\tau_{[y]}}\right), \tau_{[u]} \sim \operatorname{Uniform}(0,100) .
$$


Tabel 2. Perbandingan Penduga Langsung dengan Penduga Hierarchical Bayesian (HB) Loglogistik

\begin{tabular}{|l|c|c|c|c|}
\hline \multirow{2}{*}{ Kecamatan } & \multicolumn{2}{|c|}{ Penduga Langsung } & \multicolumn{2}{c|}{ Penduga HB } \\
\cline { 2 - 5 } & $\widehat{y}$ & Standard Error & $\widehat{y}$ & Standard Error \\
\hline VII Koto Sungai Sariak & 0,0780 & 0,00034 & 0,0779 & 0,00003 \\
\hline Batang Anai & 0,0610 & 0,00025 & 0,0613 & 0,00002 \\
\hline Lubuk Alung & 0,0870 & 0,00005 & 0,0870 & 0,00001 \\
\hline Sintuk Toboh Gadang & 0,0980 & 0,00092 & 0,0975 & 0,00008 \\
\hline Ulakan Tapakis & 0,0540 & 0,00072 & 0,0539 & 0,00004 \\
\hline Nan Sabaris & 0,0780 & 0,00033 & 0,0783 & 0,00003 \\
\hline 2 X 11 Enam Lingkung & 0,0990 & 0,00133 & 0,0992 & 0,00010 \\
\hline Enam Lingkung & 0.0940 & 0,00015 & 0,0945 & 0,00002 \\
\hline 2 X 11 Kayu Tanam & 0,0760 & 0,00101 & 0,0760 & 0,00006 \\
\hline Patamuan & 0,1340 & 0,00066 & 0,1343 & 0,00008 \\
\hline Padang Sago & 0,1590 & 0,18252 & 0,1581 & 0,00346 \\
\hline V Koto Kp. Dalam & 0,0950 & 0,00041 & 0,0948 & 0,00004 \\
\hline V Koto Timur & 0,1510 & 0,00035 & 0,1506 & 0,00005 \\
\hline Sungai Limau & 0,0840 & 0,00045 & 0,0839 & 0,00004 \\
\hline Batang Gasan & 0,1170 & 0,00163 & 0,1191 & 0,00021 \\
\hline Sungai Geringging & 0,0890 & 0,00020 & 0,0891 & 0,00002 \\
\hline IV Koto Aur Malintang & 0,1190 & 0,00024 & 0,118 & 0,00004 \\
\hline
\end{tabular}

Bentuk distribusi full conditional posterior untuk parameter $\beta_{j}$ adalah:

$$
\begin{aligned}
f\left(\beta_{j} \mid \boldsymbol{y}, \boldsymbol{\beta}_{\backslash j}, \tau_{[u]}, \tau_{[y]}\right) \propto & \left(\tau_{[u]}^{\frac{n}{2}} \times \tau_{[\beta]_{j}}^{\frac{1}{2}}\right) \\
& \times \exp \left(-\frac{1}{2}\left(\tau_{[u]} \sum_{i=1}^{n}\left(\mu_{i}-\sum_{j=1}^{k} x_{i j} \beta_{j}\right)^{2}+\tau_{[\beta]_{j}}\left(\beta_{j}-\mu_{[\beta]_{j}}\right)^{2}\right)\right) .
\end{aligned}
$$

Bentuk distribusi full conditional posterior untuk parameter $\tau_{[y]}$ adalah:

$$
\begin{aligned}
f\left(\tau_{[y]} \mid \boldsymbol{y}, \boldsymbol{\beta}, \tau_{[u]}\right) \propto & \tau_{[y]}^{a}\left(\tau_{[y]}\right)^{+\frac{n}{2}-1} \exp \left(\ln \frac{1}{\prod_{i=1}^{n} y_{i}\left[1+\exp \left(\tau_{[y]}^{\frac{1}{2}} \sum_{i=1}^{n} \ln \left(y_{i}\right)-\mu\right)\right]^{2}}\right. \\
& \left.+\left(\tau_{[y]}^{\frac{1}{2}} \sum_{i=1}^{n} \ln \left(y_{i}\right)-\mu\right)+\left(-b_{\tau_{[y]}} \times \tau_{[y]}\right)\right) .
\end{aligned}
$$

Bentuk distribusi full conditional posterior untuk parameter $\tau_{[u]}$ adalah:

$$
f\left(\tau_{[u]} \mid \boldsymbol{y}, \boldsymbol{\beta}, \tau_{[y]}\right) \sim \operatorname{Gamma}\left(\frac{n}{2}+1,\left(-\frac{1}{2} \sum_{i=1}^{n}\left(\mu_{i}-\sum_{j=1}^{k} x_{i j} \beta_{j}\right)^{2}\right)\right) .
$$


(2) Hasil estimasi tingkat kemiskinan menggunakan model Small Area Estimation dengan pendekatan Hierarchical Bayesian (HB) Loglogistik mempunyai nilai standard error yang lebih kecil jika dibandingkan dengan estimasi tingkat kemiskinan menggunakan pendugaan langsung. Oleh karena itu, dapat disimpulkan bahwa metode Small Area Estimation dengan pendekatan HB Loglogistik lebih baik daripada pendugaan langsung.

\section{Ucapan Terima kasih}

Penulis mengucapkan terima kasih kepada Hazmira Yozza, M.Si, Dr. Lyra Yulianti, dan Dr. Ferra Yanuar yang telah memberikan kritikan dan masukan sehingga makalah ini dapat diselesaikan dengan baik.

\section{Daftar Pustaka}

[1] Badan Pusat Statistik dan World Bank Institute. 2002. Dasar-Dasar Analisis Kemiskinan. Badan Pusat Statistik, Jakarta

[2] Badan Pusat Statistik Sumatera Barat. 2019. Profil Kemiskinan di Sumatera Barat September 2018. Badan Pusat Statistik Sumatera Barat, Padang

[3] Gosh, M. dan Rao J.N.K. 1994. Small Area Estimation: An Appraisal. Statistical Sciences. 9 (1) : $56-93$

[4] Kus, C. and Kaya, M.F. 2006. Estimation of Parameters of the Loglogistic Distribution Based on Progressive Censoring Using the EM Algorithm. Hacettepe Journal of Mathematics and Statistics. 35 (2) : 203 - 204

[5] Nzoufras, I. 2009. Bayesian Modeling Using Winbugs. John Wiley \& Sons, New Jersey

[6] Rao, J.N.K. 2003. Small Area Estimation. John Wiley and Sons, New York

[7] Ubaidillah, A. 2014. Small Area Estimation dengan Pendekatan Hierarchical Bayesian Neural Network untuk Pemetaan Kemiskinan di Kota Jambi. Tesis, tidak diterbitkan 